\title{
Manajemen Sisi Beban dan Optimalisasi Tingkat Konsumsi Energi Di SMK Negeri 2 Pontianak
}

\author{
Mangantar Butarbutar ${ }^{1)}$, Mulud Riyanto ${ }^{2)}$ \\ ${ }^{1,2)}$ Magister Teknik Elektro Fakultas Teknik Universitas Tanjungpura Pontianak, \\ ${ }^{1)}$ Kaprodi Teknik Otomasi Industri SMK Negeri 2 Pontianak. \\ ${ }^{2)}$ Staf Pengajar SMK Negeri 9. Pontianak \\ e-mail : mangantarbutar@gmail.com, Mulud.riyanto@gmail.com
}

\begin{abstract}
Dalam penelitian ini dilakukan manajemen beban sebagai pendekatan sistematis dan terpadu untuk melaksanakan pemanfaatan sumber daya energi di gedung praktik SMK Negeri 2 Pontianak secara efektif, efisien dan rasional tanpa mengurangi kuantitas maupun kualitas fungsi utama gedung. Langkah pelaksanaan manajemen beban ialah dengan diawali audit penggunaan tenaga listrik. Audit beban listrik ini meliputi analisis profil penggunaan tenaga listrik, mengidentifikasi pemborosan energi dan menyusun langkah pencegahan. Audit beban dilakukan terhadap konsumsi besarnya energi listrik, sistem pencahayaan, sistem pengkondisian udara dan peralatan listrik lainnya pada gedung tersebut. Proses audit energi listrik dilakukan secara bertahap yaitu audit energi awal yang kegiatannya meliputi pengumpulan data historis gedung dan penyusunan data energi bangunan gedung tersebut. Kemudian dilanjutkan pada audit energi rinci, yaitu jika diketahui bahwa nilai Intensitas Konsumsi Energi (IKE) lebih besar dari nilai IKE standar yang telah ditetapkan oleh Badan Standarisasi Nasional (BSN). Kegiatan audit energi rinci ini meliputi penelitian dan pengukuran konsumsi energi, kemudian dilanjutkan pada identifikasi peluang hemat energi. Hasil audit energi yang telah dilakukan menunjukkan bahwa tidak terjadi pemborosan energi, tetapi ada pemakaian energi yang tidak bijak. Hal ini dapat dilihat dari nilai IKE yang masih dibawah standar yaitu 99,75 kWh/m2 per tahun berdasarkan data rekening dengan jumlah konsumsi energi $58616.50 \mathrm{kWh}$ per-tahun, sedangkan standar yang ditetapkan untuk gedung perkantoran yaitu $240 \mathrm{kWh} / \mathrm{m} 2$ per tahun. Untuk penghematan disarankan dalam penyusunan penjadwalan pemakaian gedung praktik supaya disesuaikan dengan besar konsumsi energi di setiap gedung tersebut.
\end{abstract}

Keywords- Manajemen Sisi Beban, Optimalisasi Tingkat Konsumsi Energi.

\section{Pendahuluan}

Adapun kegunaan energi listrik dalam kehidupan sehari-hari dimanfaatkan untuk penerangan, pemanas, motor-motor listrik dan lain-lain. Energi yang digunakan alat listrik merupakan laju penggunaan energi (daya) dikalikan dengan waktu selama alat tersebut digunakan. Dalam waktu yang akan datang kebutuhan listrik akan terus meningkat seiring dengan adanya peningkatan dan perkembangan baik dari jumlah penduduk, jumlah investasi, perkembangan teknologi termasuk didalamnya perkembangan dunia pendidikan untuk semua jenjang pendidikan. SMK Negeri 2 Pontianak merupakan salah satu lembaga pendidikan menengah kejuruan bidang teknologi dan rekayasa yang mengkonsumsi energi listrik cukup besar dalam melakukan operasionalnya dengan daya terpasang 82.500 VA di gedung praktik dan 16500 VA di gedung teori.

Menejemen beban dilakukan untuk mengetahui kondisi beban terpakai dan terpasang juga mengendalikan atau menekan tingkat pemakaian energi listrik yang berlebihan sebagai upaya menghemat penggunaan energi listrik. Pada hari dan jam tertentu sering terjadi beban puncak dan circuit breaker trip ( pengaman arus lebih memutus arus ) sehingga terjadi pemadaman aliran listrik khususnya pada gedung praktek dan kondisi ini sangat mengganggu aktivitas proses belajar mengajar sehingga perlu dilakukannya evaluasi pemanfaatan energi dan peningkatan efisiensi serta identifikasi peluang penghematan energi di SMK N2 Pontianak.

\section{Teori Dasar}

\subsection{Konservasi Energi}

Konservasi adalah pelestarian atau perlindungan. Sedangkan untuk konservasi energi menurut PP 70 Tahun 2009 adalah upaya sistematis, terencana, dan terpadu untuk melestarikan sumber daya energi dalam negeri serta meningkatkan efisiensi pemanfaatannya. Tujuan konservasi energi adalah untuk memelihara kelestarian sumber daya alam yang berupa sumber energi melalui kebijakan pemilihan teknologi dan pemanfaatan energi secara efisien dan rasional..

2.2. Manajemen Beban

Manajemen beban adalah pengendalian penggunaan energy listrik atau bentuk lain dengan mengurangi atau mengoptimalkan jumlah pemakain tersebut dan tingkat penggunaan tersebut (permintaan). Dalam system tenaga listrik, factor beban adalah item yang harus dikendalikan atau dikelola. Item tersebut-dikendalikan oleh mereka yang dimasukkan ke dalam system manajemen energi. Manajemen energi adalah suatu program yang direncanakan dan dilaksanakan secara sistematis untuk memanfaatkan energi secara efektif dan efisien dengan melakukan perencanaan, pencatatan, pengawasan dan 
evaluasi secara kontinu tanpa mengurangi kualitas produksi dan pelayanan.

IKE dijadikan acuan untuk melihat seberapa besar konservasi energi yang dilakukan di gedung tersebut. Adapun perhitungan IKE sebagai berikut :

$$
I K E=\frac{K W h \text { total }}{\text { Luas Bangunan }}
$$

Tabel 1. Standar IKE untuk berbagai tipe/fungsi bangunan.

\begin{tabular}{|c|c|c|c|c|}
\hline \multirow[b]{2}{*}{$\begin{array}{c}\text { Tipe } \\
\text { Bangunan }\end{array}$} & \multicolumn{3}{|c|}{ Rentang IKE (KWH/m2/tahun) } & \multirow{2}{*}{$\begin{array}{c}\text { Waktu Operasional Acuan } \\
\text { (benchmark operasional } \\
\text { hours) }\end{array}$} \\
\hline & $\begin{array}{l}\text { Batas } \\
\text { bawah }\end{array}$ & Acuan & \begin{tabular}{|l|}
$\begin{array}{l}\text { Batas } \\
\text { atas }\end{array}$ \\
\end{tabular} & \\
\hline Perkantoran & 210 & 250 & 285 & $\begin{array}{l}10 \mathrm{jam} / \mathrm{hari}, 5 \mathrm{har} / \mathrm{minggu} \text {, } \\
52 \mathrm{minggu} / \mathrm{th}=2600 \mathrm{jam} / \mathrm{th}\end{array}$ \\
\hline Hotel & 290 & 350 & 400 & $\begin{array}{l}10 \mathrm{jam} / \mathrm{hari}, 5 \mathrm{har} / \mathrm{minggu} \text {, } \\
52 \mathrm{minggu} / \mathrm{th}=2600 \mathrm{jam} / \mathrm{th}\end{array}$ \\
\hline Apartemen & 300 & 350 & 400 & $\begin{array}{l}10 \mathrm{jam} / \mathrm{hari}, 5 \mathrm{har} / \mathrm{minggu} \text {, } \\
52 \mathrm{minggu} / \mathrm{th}=2600 \mathrm{jam} / \mathrm{th}\end{array}$ \\
\hline Sekola & 195 & 235 & 265 & $\begin{array}{l}10 \mathrm{jam} / \mathrm{hari}, 5 \mathrm{har} / \mathrm{minggu} \text {, } \\
52 \mathrm{minggu} / \mathrm{th}=2600 \mathrm{jam} / \mathrm{th}\end{array}$ \\
\hline $\begin{array}{l}\text { Rumah } \\
\text { Sakit }\end{array}$ & 320 & 400 & 450 & $\begin{array}{l}10 \mathrm{jam} / \mathrm{hari}, 5 \mathrm{hari} / \mathrm{minggu} \text {, } \\
52 \mathrm{minggu} / \mathrm{th}=2600 \mathrm{jam} / \mathrm{th}\end{array}$ \\
\hline Pertokoan & 350 & 450 & 500 & $\begin{array}{l}10 \mathrm{jam} / \mathrm{hari}, 5 \mathrm{hari} / \mathrm{minggu} \text {, } \\
52 \mathrm{minggu} / \mathrm{th}=2600 \mathrm{jam} / \mathrm{th}\end{array}$ \\
\hline
\end{tabular}

Sumber : Pergub DKI No. 38 tahun 2012

Jika pada rentang lebih rendah daripada batas bawah, maka bangunan gedung tersebut dikatakan hemat sehingga perlu mempertahankan dengan melaksanakan SOP dan pemeliharaan yang sistematis. Jika di antara batas bawah dan acuan, maka bangunan gedung tersebut dikatakan agak hemat sehingga perlu meningkatkan kinerja dengan melakukan tuning up. Jika di antara acuan dan batas atas, maka bangunan gedung tersebut dikatakan agak boros sehingga perlu melakukan beberapa perubahan. Bila di atas batas atas, maka perlu dilakukan retrofitting atau replacement.

\subsection{Klasifikasi Beban}

Berdasarkan jenis konsumen energi listrik, secara garis besar, ragam beban dapat diklasifikasikan ke dalam :

1. Beban rumah tangga.

2. Beban komersial.

3. Beban industry.

4. Beban Fasilitas Umun

\subsection{Karakteristik Umum Beban Listrik}

Tujuan utama dari sistem distribusi tenaga listrik ialah mendistribusikan tenaga listrik dari gardu induk atau sumber ke sejumlah pelanggan atau beban. Suatu faktor utama yang paling penting, dalam perencanaan system distribusi adalah karakteristik dari berbagai beban. Karakteristik beban diperlukan agar sistem tegangan dan pengaruh thermis dari pembebanan dapat dianalisis dengan baik.

\section{Faktor Beban (load factor)}

Faktor beban adalah perbandingan antara beban rata rata terhadap beban puncak yang diukur dalam suatu periode tertentu. Faktor beban dapat dihitung dengan persamaan :

$$
L_{f}=\frac{E_{r}}{E_{p}}
$$

Dimana : $E_{r}=$ Beban rata-rata

$$
E_{p}=\text { Beban Puncak }
$$

2. Faktor Beban harian rata - rata

Faktor beban harian rata - rata merupakan dasar dari pada faktor beban tahunan total.Selanjutnya, dapat dilihat beban puncak bulanan rata - rata terhadap beban puncak tahunan, misalkan $F_{b t}=$ puncak tahuanan (annual load faktor), maka ini dapat dihitung sebagai berikut :

$$
F_{b t}=P_{p b} \times \frac{F_{b h}}{P_{p h}}
$$

Dimana :

$$
\begin{aligned}
& F_{b t}=\text { faktor beban tahunan } \\
& F_{b h}=\text { faktor beban harian } \\
& P_{p h}=\text { beban puncak rata }- \text { rata harian } \\
& P_{p b}=\text { beban puncak rata }- \text { rata bulanan }
\end{aligned}
$$

\section{Faktor Penilaian Beban}

Faktor-faktor penilaian beban adalah faktor yang dapat memberikan gambaran mengenai karakteristik beban, baik dari segi kuantitas pembebanannya maupun dari segi kualitasnya.

Beban terpasang dari suatu sistem adalah jumlah total daya dari seluruh peralatan sesuai dengan $\mathrm{KW}$ atau KVA yang tertulis pada papan nama (name plat) peralatan yang akan dilayani oleh sistem tersebut.

Jadi

$$
\begin{aligned}
& \quad \mathrm{PL}=\sum_{i=1}^{n} \mathrm{P}_{\mathrm{i}} \\
& \text { Dimana : } \\
& \mathrm{P}_{\mathrm{i}}=\text { rating KVA dari alat } \mathrm{i} \\
& \mathrm{n}=\text { jumlah alat yang terhubung ke sistem. }
\end{aligned}
$$

\section{h. Faktor Beban (Load Factor)}

Faktor beban adalah perbandingan antara beban rata-rata selama interval tertentu dengan beban puncak yang terjadi pada interval yang sama.

$$
F_{L D}=\frac{P_{a v}}{P_{\max }}
$$

dimana: $P_{a v}=$ beban rata-rata dan $P_{\max }=$ beban puncak. Faktor beban adalah perbandingan antara beban rata - rata terhadap beban puncak dalam periode tertentu.

i. Faktor rugi-rugi (Loss Factor)

Faktor rugi-rugi (fLs) didefinisikan sebagai perbandingan antara rugi-rugi daya rata-rata terhadap rugi-rugi daya beban puncak dalam selang waktu tertentu.

$$
F_{L s}=\frac{P_{L S a v}}{P_{L S \max }}
$$

\section{Jenis Beban Listrik}

\subsection{Beban Penerangan}

Banyaknya cahaya yang dihasilkan oleh suatu lampu disebut fluks luminus dengan satuan lumen. Efisiensi penerangan lampu bertambah dengan bertambahnya daya lampu. Rugi-rugi ballast harus ikut diperhitungkan dalam menentukan efisiensi sistem lampu . Untuk menentukan jumlah lampu penerangan dalam suatu ruangan dapat menggunakan persamaan :

Dimana :

$$
N=\frac{E \times L \times W}{\emptyset \times L L F \times C_{u} \times n}
$$

- $\quad \mathrm{N}=$ Jumlah titik lampu 
- $\quad \mathrm{E}=$ Kuat penerangan (Lux), rumah atau apartemen standar 100lux -250lux

- $\mathrm{L}=$ Panjang (Length) ruangan dalam satuan meter

- $\mathrm{W}=$ Lebar (Width) ruangan dalam satuan meter.

- $\varnothing=$ Total nilai pencahayaan lampu dalam satuan lumen

- $\quad$ LLF = (Light Loss Factor $)$ atau Faktor kehilangan atau kerugian cahaya, biasa nilainya antara $0,7-$ 0,8

- $\mathrm{Cu}=($ Coeffesien of Utillization $)$

- $\mathrm{n}=$ Jumlah lampu dalam 1 titik

Tingkat pencahayaan memiliki nilai yang berbeda-beda sesuai dengan jenis dan fungsi ruangan tersebut.

3.2. Beban AC

Untuk melakukan audit terhadap sistem AC, diperlukan informasi mengenai keadaan sistem, seperti spesifikasi unit, jumlah unit, periode penggunaan. Analisis perhitungan untuk mengetahui perbedaan konsumsi energi pada sistem pendingin udara ( AC ) sebagai berikut:

1. Perhitungan Data Efisiensi AC

2. Perhitungan AC split per kamar

3. Perhitungan beban AC

4. Perhitungan kapasitas $\mathrm{AC}$ berdasarkan jumlah ruangan per bulan.

BTU adalah perhitungan suatu kebutuhan kapasitas pendingin (AC) untuk kebutuhan ruangan yang akan digunakan agar diperoleh hasil yang hemat dan optimal. Cara menghitung kebutuhan kapasitas ac pada suatu ruangan

Kebutuhan $B T U=\frac{(W \times H \times I \times L \times E)}{60}$ dimana :

- $\quad \mathrm{W}=$ Panjang ruang (meter)

- $\mathrm{H}=$ Tinggi ruang (meter)

- $\quad$ I = Insulasi (nilai 10 jika berada dilantai bawah \& nilai 18 jika berada di lantai atas)

- $\mathrm{L}=$ Lebar ruang (meter)

- $\mathrm{E}=$ Hadap ruangan

Nilai 16 jika dinding terpanjang menghadap utara Nilai 17 jika dinding terpanjang menghadap timur Nilai 18 jika dinding terpanjang menghadap selatan

Nilai 20 jika dinding terpanjang menghadap barat

3.3. Motor Listrik.

Motor listrik merupakan sebuah benda yang mengubah energi listrik menjadi energi mekanik. Efisiensi daya motor dapat dihitung denganpersamaan : :

$$
\eta=\frac{P_{o}}{P_{i}} \times 100 \%
$$

Dimana: $\eta$ : Efisiensi operasi motor (\%)

$P_{o} \quad$ : Daya yang keluar $(\mathrm{kW})$

$P_{i} \quad$ : Daya masuk $(\mathrm{kW})$

Namun jika kesulitan dalam mengetahui besar efisiensi secara langsung, maka dapat dilakukan metode pengukuran daya masuk untuk menghitung beban terlebih dahulu. Tahap pertama adalah menentukan daya masuk dengan menggunakan persamaan:

$$
P_{i}=\frac{V \times I \times P F \sqrt{3}}{1000}
$$

Dimana: $P_{i}$ : Daya tiga fasa $(\mathrm{kW})$

$\mathrm{V}$ : Nilai tegangan terukur (volt)

I : Nilai arus terukur (ampere)

PF : Faktor daya dalam desimal

Lalu menentukan nilai daya masuk dengan mengambil nilai pada nameplate dengan menggunakan persamaan:

$$
P_{r}=H P \times \frac{0.746}{\eta_{\mathrm{r}}}
$$

Dimana:

Pr: Daya masuk beban penuh $(\mathrm{kW})$

$H P$ : Nilai daya pada nameplate $(\mathrm{H})$

$\eta_{\mathrm{r}}$ : Efisiensi pada beban penuh ( nilai pada nameplate )

Selanjutnya menentukan daya keluar yang dinyatakan dalam $\%$, yaitu dengan menggunakan persamaan:

$$
P_{o}=\frac{P_{i}}{P_{r}} 100 \%
$$

Dimana: $\quad P_{o}$ : Daya keluar yang dinyatakan dalam \% nilai daya nominal

$$
\begin{aligned}
& P_{i} \text { : Daya tiga fasa terukur }(\mathrm{kW}) \\
& P_{r} \text { : Daya masuk beban penuh }(\mathrm{kW})
\end{aligned}
$$

2.4. Macam - Macam Daya Listrik.

Dalam listrik arus bolak-balik (AC) terdapat rumus daya listrik untuk satu phasa dan tiga phasa. Pada rumus daya listrik satu phasa tidak terlepas dari rumus segitiga daya.

Dimana pengertian umum dari segitiga daya adalah suatu hubungan antara daya nyata, daya semu, dan daya reaktif, yang dapat dilihat hubungannya pada gambar bentuk segitiga di bawah ini :

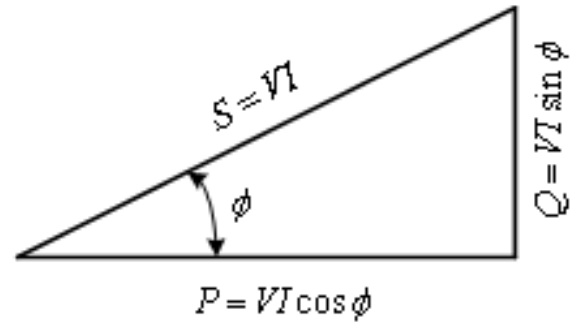

Gambar 1. Segitiga Daya

1. Daya Listrik 1 Phasa.

Rumus daya listrik 1 phasa dapat dinyatakan oleh persamaan :

a. Daya Semu ( $S$ ) dengan

$$
S=V \times I
$$

dimana : $S=$ daya semu ( Volt Ampere )

$$
\begin{aligned}
& \mathrm{V}=\text { tegangan ( Volt ) } \\
& \mathrm{I}=\text { Arus (Ampere ) }
\end{aligned}
$$

b. Daya Aktif ( $\mathrm{P}$ ) dengan rumus :

$$
\begin{aligned}
P= & V \times I \times \cos \emptyset \\
\operatorname{dimana}: & \mathrm{P}=\text { daya aktif }(\text { Watt }) \\
\emptyset & =\text { sudut factor daya }
\end{aligned}
$$

c. Daya Reaktif ( Q ) dengan rumus :

$$
Q=V \times I \times \sin \emptyset
$$

dimana :

$$
\mathrm{Q}=\text { daya reaktif ( Volt Ampere Reaktif ) }
$$

Sedangkan untuk mencari nilai energi (W), digunakan persamaan berikut:

$$
W=P \times t
$$


dimana: $\quad \mathrm{W}=$ energi listrik $(\mathrm{kWh})$

$\mathrm{P}$ = daya yang digunakan $(\mathrm{kW})$

$\mathrm{t}=$ waktu (h)

2. Daya Listrik 3 Phasa.

Rumus daya listrik 3 phasa dapat dinyatakan oleh persamaan :

a. Daya Semu ( $S$ ) dengan rumus :

$$
S=\sqrt{3} \times V \times I
$$

dimana : $S=$ daya semu ( Volt Ampere )

$$
\mathrm{V}=\text { tegangan ( Volt ) }
$$$$
\mathrm{I}=\operatorname{Arus}(\text { Ampere ) }
$$

$$
\begin{aligned}
\text { b. Daya } \text { Aktif }(\mathrm{P}) & \text { dengan rumus : } \\
P=\sqrt{3} \times V \times I \times \cos \emptyset & (17) \\
\text { dimana: } & \mathrm{P}=\text { daya aktif }(\text { Watt }) \\
& \emptyset=\text { sudut factor daya }
\end{aligned}
$$

c. Daya Reaktif ( Q ) dengan rumus :

$$
Q=\sqrt{3} \times V \times I \times \sin \emptyset
$$

dimana :

$$
\mathrm{Q}=\text { daya reaktif ( Volt Ampere Reaktif ) }
$$

\section{Metodologi Penelitian}

Manajemen beban adalah pengendalian penggunaan energy listrik. Dalam proses ini meliputi adanya konsep konservasi energi yaitu kontrol energi yang merupakan pengurangan jumlah penggunaan $\mathrm{kWh}$. Kontrol energi yang dilakukan adalah dengan metodologi kontrol beban, seperti pengurangan tingkat pencahayaan, kontrol waktu dengan penjadwalan pemakaian gedung, penggunaan peralatan dan perlengkapan yang mengkonsumsi energi listrik,

3.2. Waktu dan Tempat Penelitian

Penelitian ini dilakukan dengan mengambil tempat di gedung praktik SMK Negeri 2 Pontianak yang meliputi : gedung teknik mesin/otomotif, gedung teknik ketenagalistrikan, gedung teknik elektronika, gedung laboratorium komputer, gedung teknik gambar, gedung broadcasting dan gedung pemancar smk tv dengan nomor ID pelanggan 211.000.395.939 dan tarif daya S2/ 82500 VA.

Adapun gambar dan lokasi gedung SMK Negeri 2 Pontianak diperlihatkan dalam gambar 3 berikut :

\section{DENAH GEDUNG PRAKTIK SIMK NEGER 2 PONTIANAK}

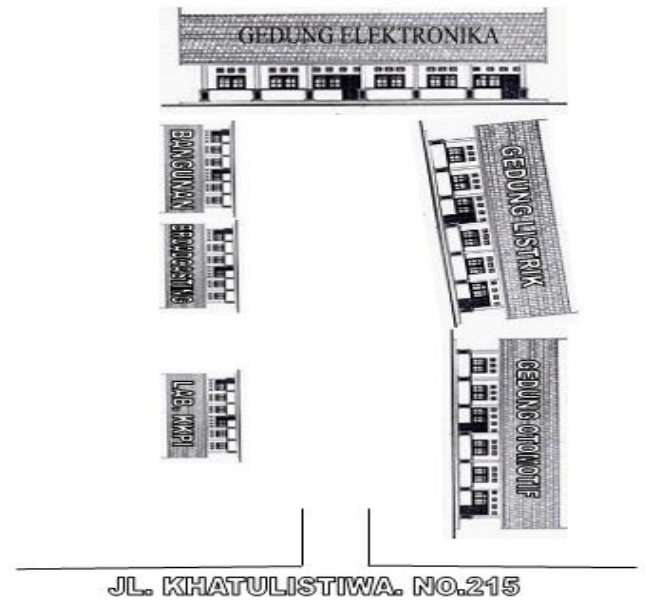

Gambar 2. Gambar Lokasi bangunan SMK Negeri 2 Pontiank.
Bangunan gedung SMK Negeri 2 Pontianak berlokasi di Jln. Khatulistiwa No.215 Pontianak . Luas lantai keseluruhan gedung teori adalah $2.173 \mathrm{~m}^{2}$ dan luas lantai keseluruhan gedung praktik adalah $2.584 .5 \mathrm{~m}^{2}$.

3.3. Alat Pengukuran

Pengukuran yang dilakukan adalah dengan mengukur pemakaian energi tiap unit peralatan yang bekerja di gedung praktik SMK Negeri 2 Pontianak. Yang perlu diukur secara langsung pada sistem kelistrikan adalah arus, daya, faktor daya dan konsumsi energi. Pada sistem tata udara, pengukuran dilakukan terhadap daya konsumsi ac. Pada sistem tata cahaya, pengukuran dilakukan terhadap intensitas penerangan. Peralatan pengukuran yang digunakan terdiri dari alat ukur faktor daya atau cosphi, $\mathrm{kWh}$ meter, tang amper, amperemeter, voltmeter, luxmeter dan meteran.

3.4. Mekanisme Pelaksanaan Penelitian

Mekanisme pelaksanaan penelitian audit energi pada bangunan gedung praktik SMK Negeri 2 Pontianak ini pada intinya terdiri dari dua bagian, yaitu : audit energi awal dan audit energi rinci.

3.4.1. Audit Energi Awal

Kegiatan audit energi awal meliputi : Pengumpulan data energi bangunan dengan data-data historis yang tersedia dan tidak memerlukan pengukuran.

3.4.2. Audit Energi Rinci

Audit energi rinci dilakukan apabila nilai IKE bangunan lebih besar dari target nilai IKE standar.

Langkah kerja dalam penelitian ini berdasarkan flowchart yang ditunjukkan pada gambar 5 berikut.

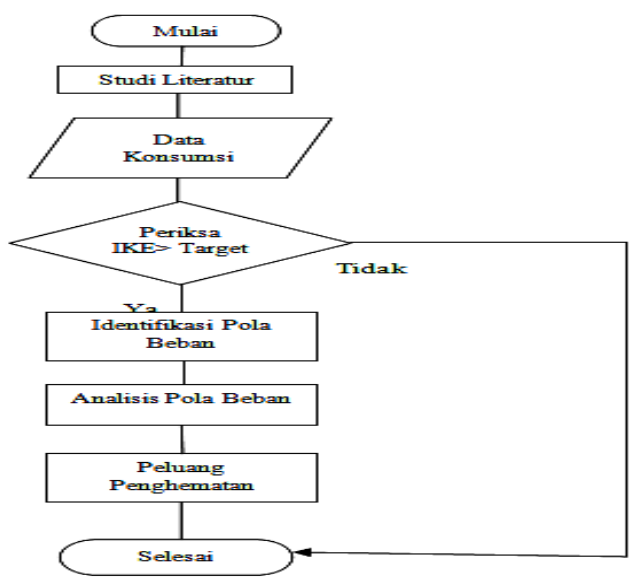

Gambar 3. Diagram alir penelitian.

3.5. Pengolahan data.

Penelitian ini menggunakan jenis data primer dan data sekunder, baik yang bersifat kualitatif maupun kuantitatif. Berdasarkan jenis dan sumber datanya, pengumpulan data yang digunakan pada penelitian ini adalah sebagai berikut

\subsubsection{Pengumpulan Data Sekunder.}

Data sekunder (observasi) merupakan data yang tidak didapat secara langsung dari sumber pertama tetapi sudah dalam bentuk dokumen tertulis. Dalam penelitian ini data sekunder yang diperlukan adalah :

a. Denah bangunan seluruh ruangan.

b. Jadwal penggunaan ruangan.

c. Besarnya daya tersambung dari sumber listrik PLN. 
d. Pembayaran rekening listrik bulanan bangunan gedung selama satu tahun terakhir.

e. Tarif dasar listrik.

f. Tingkat hunian bangunan (occupancy rate).

3.5.2. Pengambilan Data Primer.

Data primer adalah data yang diperoleh melalui hasil pengukuran, perhitungan, dan pengamatan langsung di lapangan. Untuk mendapatkan data yang akurat diperlukan seperangkat alat ukur. Dalam penelitian ini data primer yang diukur adalah :

a. Rincian luas bangunan dan luas total bangunan $\left(\mathrm{m}^{2}\right)$.

b. Daya listrik total yang dibutuhkan.

c. Daya listrik terpasang per $\mathrm{m}^{2}$ luas lantai untuk keseluruhan bangunan.

d. Intesitas Konsumsi Energi bangunan.

e. Biaya pemakaian energi bangunan.

3.5.3. Survei Lapangan.

Survei dilakukan dengan cara mengidentifikasi jumlah, jenis, dan spesifikasi peralatan yang menggunakan energi listrik di gedung praktik sekolah SMK Negeri 2 Pontianak, peralatan gedung praktik sebagai berikut :

a. Gedung praktik teknik mesin/otomotif.

b. Gedung teknik ketenagalistrikan.

c. Gedung praktik teknik elektronika

d. Gedung teknik gambar.

e. Gedung broadcasting.

f. Gedung laboratorium computer.

Pengolahan dan analisis data menggunakan analisis deskriptif, analisis IKE, identifikasi peluang konservasi energi melalui pendekatan financial assessment. Analisis deskriptif merupakan metode analisis yang digunakan dengan tujuan untuk memperoleh gambaran secara mendalam dan objektif mengenai objek penelitian.

Perhitungan dan analisis intensitas konsumsi energi listrik dilakukan dengan cara membandingkan energi yang digunakan selama satu tahun atau per bulan dengan luas bangunan gedung. Kemudian, hasil perhitungan dibandingkan dengan standar yang telah ditetapkan dalam Standar Nasional Indonesia.

3.5.4. Analisis peluang hemat energi.

Apabila peluang hemat energi ini telah dikenali sebelumnya, maka perlu di tindaklanjuti dengan analisis peluang hemat energi, yaitu dengan cara membandingkan potensi perolehan hemat energi dengan biaya yang harus dibayar untuk pelaksanaan rencana penghematan energi yang direkomendasikan. Analisis peluang hemat energi dilakukan dengan usaha-usaha:

a. Mengurangi sekecil mungkin pemakaian energi ( mengurangi $\mathrm{kW}$ dan jam operasi)

b. Memperbaiki kinerja peralatan

c. Penjadwalan jam pelajaran di gedung praktik untuk menjaga keseimbangan pemakaian konsumsi daya listrik tiga phasa.

2. Pemanfaatan energi yaitu di dalamnya terdapat

a. Langkah-langkah perbaikan efisiensi penggunaan energi tanpa biaya, misalnya merubah prosedur pengoperasian.

b. Langkah-langkah perbaikan dengan biaya yang rendah.

3.6. Tata Cara Pengambilan Data

3.6.1. Pengukuran Optimasi Pemakaian Daya Listrik
Prosedur umum perhitungan besarnya pemakaian daya listrik untuk system penerangan buatan dalam rangka penghematan energi sebagai berikut :

a. Menentukan tingkat penerangan rata-rata (lux) sesuai dengan fungsi ruangan.

b. Menghitung jumlah Fluks Luminus (lumen) dan jumlah lampu yang diperlukan.

c. Menghitung jumlah daya terpasang dan memeriksa apakah daya terpasang per meter persegi tidak melampaui angka maksimum yang telah ditentukan.

3.6.2 Pengukuran Sistem Tata Udara

Perhitungan untuk mengevaluasi sistem tata udara keseluruhan meliputi pengukuran kapasitas pendingin pada evaporator, pengukuran seluruh daya listrik yang diperlukan untuk menyelenggarakan kenyamanan dalam gedung tersebut.

3.6.3. Konservasi Energi Peralatan Praktik

Adapun pelaksanaan konservasi energi pada peralatan praktik yakni :

a. Pencatatan berbagai macam peralatan tiap-tiap gedung praktik dengan kapasitasnya dan berapa lama kira-kira pemakaian dalam sistem pengamatan.

b. Pengamatan secara rutin konsumsi energi listrik untuk pemakaian seluruh gedung (dengan $\mathrm{kWh}$ meter).

c. Pencatatan secara rutin nilai tagihan PLN yang diterima tiap bulan.

d. Pencatatan lain sehubungan dengan adanya optimalisasi, standarisasi peralatan gedung praktik serta cara-cara pengelolaannya.

\subsection{Variabel Penelitian.}

Variabel penelitian meliputi jumlah pemakaian energi berdasarkan audit energi awal dan audit energi rinci, serta peluang penghematan berdasarkan kondisi dilapangan. Pada audit energi awal akan dihitung besarnya intensitas konsumsi energi ( IKE ) berdasarkan observasi penggunaan energi listrik secara detail dengan berbagai peralatan yang mengkonsumsi energi listrik dan penggunaannya.

Dalam analisa pemakaian energi listrik di sekolah, beberapa variable menjadi perhatian karena dapat memberikan kontribusi penghematan energi listrik yaitu kecenderungan pemakaian energi listrik pada penjadwalan jam pembelajaran praktik. Disini akan diamati apakah pemakaian energi listrik meningkat pada hari tertentu. Profil beban harian ini akan dapat diketahui kapasitas pemakaian pada saat beban puncak (WBP) dan pada saat di luar beban puncak (LWBP). Bila pada WBP beban hari tertentu dari penjadwalan pembelajaran lebih tinggi, maka akan dipelajari kemungkinan untuk menggeser jadwal pemakaian gedung praktik supaya beraktivitas pada saat di luar beban puncak (LWBP).

\section{Pengukuran dan Analisis Hasil Pengukuran \\ 4.1. Pengukuran.}

Dalam penelitian ini, pengukuran arus dan beban listrik dilakukan di gedung praktik SMK Negeri 2 Pontianak sebagai berikut :

1. Bengkel Teknik Otomotif.

2. Bengkel Teknik Ketenagalistrikan.

3. Bengkel Teknik Elektronika. 
4. Bengkel Teknik Gambar.

5. Bengkel Broadcasting.

6. Bengkel komputer

Besar tarif daya listrik yang ditetapkan oleh kementerian Energi Sumber Daya Mineral (ESDM) tahun 2016 diperlihatkan pada tabel 2.

\begin{tabular}{|c|c|c|c|}
\hline No. & Golongan Tarif & Daya & Tarif \\
\hline 1. & Rumah Tangga & & Per kWh \\
\hline & $\mathrm{R}-1 / \mathrm{TR}$ & $1.300 \mathrm{VA}$ & Rp 1.392 \\
\hline & $\mathrm{R}-1 / \mathrm{TR}$ & $2.200 \mathrm{VA}$ & Rp 1.392 \\
\hline & $\mathrm{R}-2 / \mathrm{TR}$ & $\begin{array}{l}3.500 \mathrm{VA}- \\
5.500 \mathrm{VA}\end{array}$ & $\operatorname{Rp} 1.392$ \\
\hline & $\mathrm{R}-3 / \mathrm{TR}$ & $6.600 \mathrm{VA}$ & Rp 1.392 \\
\hline 2. & Bisnis & & \\
\hline & $\mathrm{B}-2 / \mathrm{TR}$ & $\begin{array}{l}6.600 \mathrm{VA}- \\
200 \mathrm{kVA}\end{array}$ & $\operatorname{Rp} 1.392$ \\
\hline & B-3/TM & $\begin{array}{l}\text { di atas } 200 \\
\mathrm{kVA}\end{array}$ & Rp 1.071 \\
\hline 3. & Industri & & \\
\hline & $\mathrm{I}-3 / \mathrm{TM}$ & $\begin{array}{l}\text { di atas } 200 \\
\mathrm{kVA}\end{array}$ & Rp 1.071 \\
\hline & $\mathrm{I}-4 / \mathrm{TT}$ & $\begin{array}{l}30.000 \mathrm{kVA} \mathrm{ke} \\
\text { atas }\end{array}$ & Rp 959 \\
\hline & $\begin{array}{l}\text { Gedung } \\
\text { pemerintah }\end{array}$ & & \\
\hline & $\mathrm{P}-1 / \mathrm{TR}$ & $\begin{array}{l}6.600 \mathrm{VA}- \\
200 \mathrm{kVA}\end{array}$ & Rp 1.392 \\
\hline & $\mathrm{P}-2 / \mathrm{TM}$ & $\begin{array}{l}\text { di atas } 200 \\
\text { kVA }\end{array}$ & Rp1.071 \\
\hline
\end{tabular}

TR: Tegangan Rendah, TM: Tegangan Menengah, TT: Tegangan Tinggi

SMK Negeri 2 Pontianak adalah lembaga pemerintah di bawah naungan kementerian pendidikan nasional dengan nomor ID pelanggan 211.000.395.939 dan tarif daya S2/ 82500 VA, sehingga tarif listrik yang di berlakukan terhadap gedung SMK Negeri 2 Pontianak adalah golongan tarif gedung pemerintah yaitu $\mathrm{P}-1 / \mathrm{TR}$ dengan daya $6600 \mathrm{VA}-200 \mathrm{kVA}$.

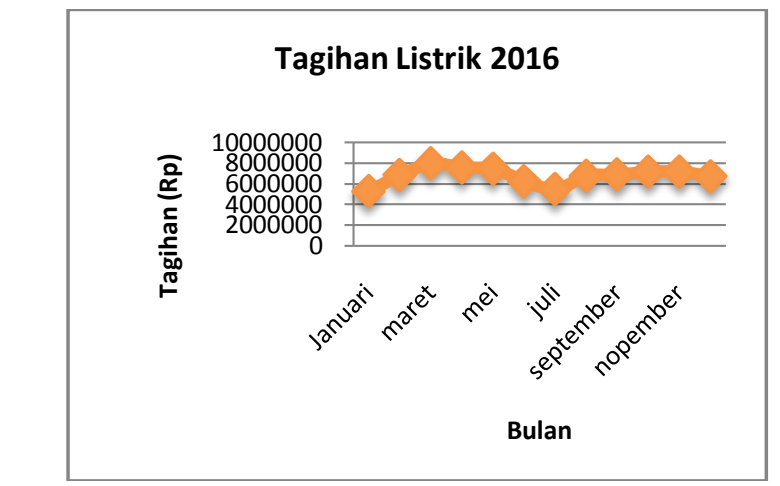

Sumber : Olahan Data (2017)

Gambar 4. Grafik tagihan listrik bulanan tahun 2016 SMK Negeri 2 Pontianak.

Setiap gedung mempunyai beberapa ruangan sesuai dengan penggunaan untuk praktik program studi tersebut. Ukuran masing-masing gedung praktik SMK Negeri 2 Pontianak diperlihatkan pada grafik.

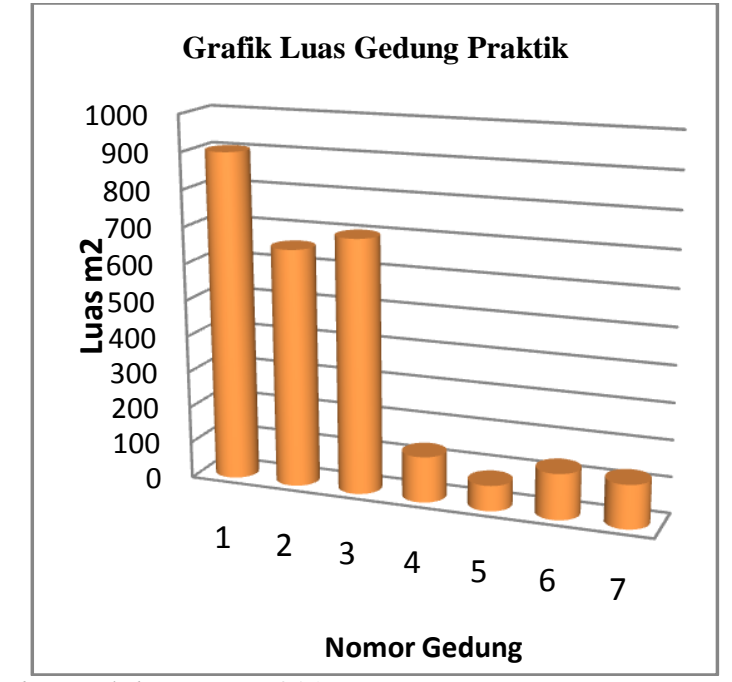

Sumber : Olahan Data ( 2017 )

Gambar 5. Grafik luas masing-masing gedung praktik SMK Negeri 2 Pontianak.

Peralatan praktik disetiap jurusan mempunyai karakteristik yang berbeda sesuai kebutuhan mata pelajaran program studi tersebut. Pada umumnya peralatan praktik bengkel yang banyak mengkonsumsi daya adalah peralatan yang menggunakan motor induksi baik satu phasa maupun tiga phasa. Rekapitulasi jumlah peralatan praktik dan kapasitas daya per-unit sesuai name plate masing-masing peralatan diperlihatkan pada tabel 3 .

Tabel 3. Rekapitulasi Daftar Peralatan Praktik SMK Negeri 2 Pontianak.

\begin{tabular}{|c|c|c|c|c|}
\hline NO & Program Keahlian & Nama Alat & Jumlah & $\begin{array}{l}\text { Kapasitas } \\
\text { Daya/unit }\end{array}$ \\
\hline \multirow[t]{10}{*}{1.} & \multirow{10}{*}{\begin{tabular}{|l|} 
Teknik \\
Mesin/Otomotif
\end{tabular}} & Mesin bubut & 3 & $3.75 \mathrm{~kW}$ \\
\hline & & \begin{tabular}{|l} 
Mesin press \\
\end{tabular} & 2 & $3 \mathrm{HP}$ \\
\hline & & Mesin press & 2 & $1 \mathrm{HP}$ \\
\hline & & Gerinda & 6 & $375 \mathrm{~W}$ \\
\hline & & Mesin las & 2 & $225 \mathrm{~A}, 29 \mathrm{~V}$ \\
\hline & & Cas aki & 1 & $220 \mathrm{~V}, 5.8 \mathrm{~A}$ \\
\hline & & Kompressor & 2 & $0.5 \mathrm{~kW}$ \\
\hline & & Kompressor & 1 & $7.5 \mathrm{~kW}$ \\
\hline & & Car lift & 1 & $3.75 \mathrm{~kW}$ \\
\hline & & Komputer & 4 & $150 \mathrm{~W}$ \\
\hline \multirow[t]{5}{*}{2.} & \multirow{5}{*}{$\begin{array}{l}\text { Teknik } \\
\text { Ketenagalistrikan }\end{array}$} & \begin{tabular}{|l|} 
Solder \\
\end{tabular} & 75 & $40 \mathrm{~W}$ \\
\hline & & Mesin las & 1 & $225 \mathrm{~A}, 29 \mathrm{~V}$ \\
\hline & & Motor Induksi & 10 & $0.75 \mathrm{~kW}$ \\
\hline & & Gerinda & 3 & $375 \mathrm{~W}$ \\
\hline & & Komputer & 18 & $150 \mathrm{~W}$ \\
\hline \multirow[t]{2}{*}{3.} & \multirow[t]{2}{*}{ Teknik Elektronika } & Solder & 75 & $40 \mathrm{~W}$ \\
\hline & & Komputer & 10 & $150 \mathrm{~W}$ \\
\hline 4. & Komputer (KKPI) & Komputer PC & 75 & $150 \mathrm{~W}$ \\
\hline 5. & \begin{tabular}{|l|} 
Teknik Gambar \\
\end{tabular} & Komputer PC & 18 & $150 \mathrm{~W}$ \\
\hline 6. & Broad casting & Komputer PC & 18 & $150 \mathrm{~W}$ \\
\hline
\end{tabular}

Sumber : Olahan Data (2017)

Penerangan (lampu) di gedung praktik pada umumnya menggunakan lampu TL 2x40W dalam satu armature dan instalasinya masih belum ada perombakan. Pendingin udara (AC) masih terbatas penggunaannya, hanya sebagian ruangan yang menggunakan ac misalnya ruangan guru dan ruangan komputer. Dibawah ini diperlihatkan jumlah dan besar konsumsi energi listrik penerangan dan pendingin di masing-masing ruangan. 
Tabel 4. Besaran kebutuhan energi listrik di gedung praktik SMK Negeri 2 Pontianak.

\begin{tabular}{|c|c|c|c|c|c|}
\hline \multicolumn{5}{|c|}{ Jumlah kebutuhan energil listik di gedung praktik } \\
\hline No. & Gedung Praktik & $\begin{array}{c}\text { Daya (W) } \\
\text { AC }\end{array}$ & $\begin{array}{c}\text { Daya (W) } \\
\text { Lampu }\end{array}$ & $\begin{array}{c}\text { Daya (W) } \\
\text { Peralann }\end{array}$ & Jumlah \\
\hline 1 & Listrik & 2340 & 4640 & 8590 & 15570 \\
\hline 2 & Elektro & 1170 & 4640 & 19650 & 25460 \\
\hline 3 & Otomotif & 1170 & 4000 & 46644 & 51814 \\
\hline 4 & Komputer & 4680 & 1840 & 11250 & 17770 \\
\hline 5 & Gambar & 1170 & 2000 & 2700 & 5870 \\
\hline 6 & Broadcasting & 4680 & 2000 & 2700 & 9380 \\
\hline & Total & 15210 & 19120 & 91534 & 125864 \\
\hline
\end{tabular}

Sumber : Olahan Data ( 2017 )

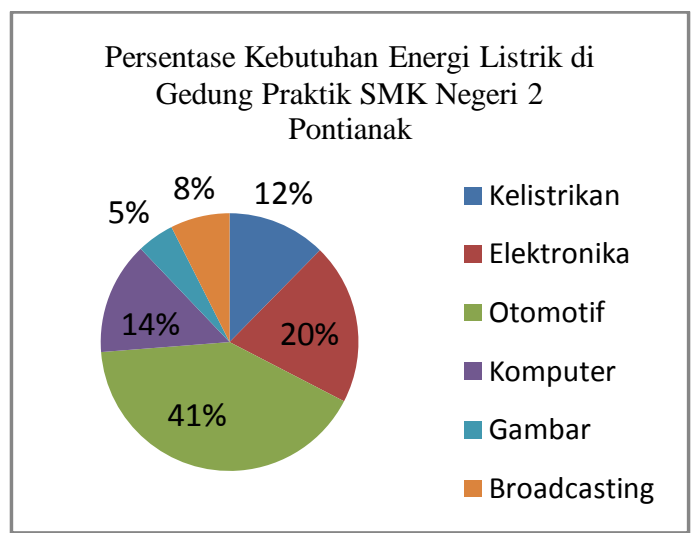

Gambar 6. Persentase kebutuhan energi listrik di gedung praktik SMK Negeri 2 Pontianak.

Tabel. 5. Konsumsi energi berdasarkan luas dan kondisi ruangan

\begin{tabular}{|c|c|c|c|c|c|}
\hline $\begin{array}{l}\text { Gedung } \\
\text { Praktik }\end{array}$ & $\begin{array}{l}\text { Luas } \\
\text { Gedung } \\
\left(m^{2}\right) \\
\end{array}$ & \begin{tabular}{|l} 
Luas \\
Ber- \\
$\mathrm{AC}$ \\
$\left(\mathrm{m}^{2}\right)$ \\
\end{tabular} & $\begin{array}{l}\text { Luas } \\
\text { Non- } \\
\text { AC } \\
\left(m^{2}\right)\end{array}$ & $\begin{array}{l}\text { Konsumsi } \\
\text { energi per- } \\
\text { tahun ruang } \\
\text { ber-ac } \\
\end{array}$ & $\begin{array}{l}\text { Konsumsi } \\
\text { energi per-tahun } \\
\text { nuang non ac }\end{array}$ \\
\hline Listrik & 654.5 & 56 & 598.5 & \multirow{7}{*}{$\begin{array}{c}31636.8 \\
\mathrm{kWh} / \mathrm{m}^{2} / \mathrm{thn}\end{array}$} & \multirow{7}{*}{$\begin{array}{c}230160.32 \\
\mathrm{kWh} / \mathrm{m}^{2} / \mathrm{thn}\end{array}$} \\
\hline Elektro & 697 & 24 & 673 & & \\
\hline Otomotif & 901 & 24 & 877 & & \\
\hline Komputer & 128 & 128 & 0 & & \\
\hline Gambar & 126 & 18 & 108 & & \\
\hline Broadcasting & 126 & 126 & 0 & & \\
\hline Total & 2632.5 & 376 & 2256.5 & & \\
\hline
\end{tabular}

Sumber : Olahan Data ( 2017 )

Pengukuran arus listrik dilakukan pada panel pembagian daya tiga phasa dari sumber PLN ke masingmasing gedung praktik. Alat ukur yang digunakan yaitu tang ampere, volt meter dan ampere meter yang sebelum mengukur terlebih dahulu di kalibrasi. Pembagian daya listrik dari panel utama ke masing-masing sub panel ke gedung praktik terdiri dari empat jalur yaitu :

1. Jalur 1 ke gedung praktik otomotif.

2. Jalur 2 ke gedung praktik ketenagalistrikan.

3. Jalur 3 ke gedung praktik elektronika, gedung gambar, gedung broad casting.
4. Jalur 4 ke gedung praktik computer.

Untuk melakukan perhitungan besarnya konsumsi energi listrik di asumsikan tegangan 380 Volt dengan factor daya sebesar 0.90 .

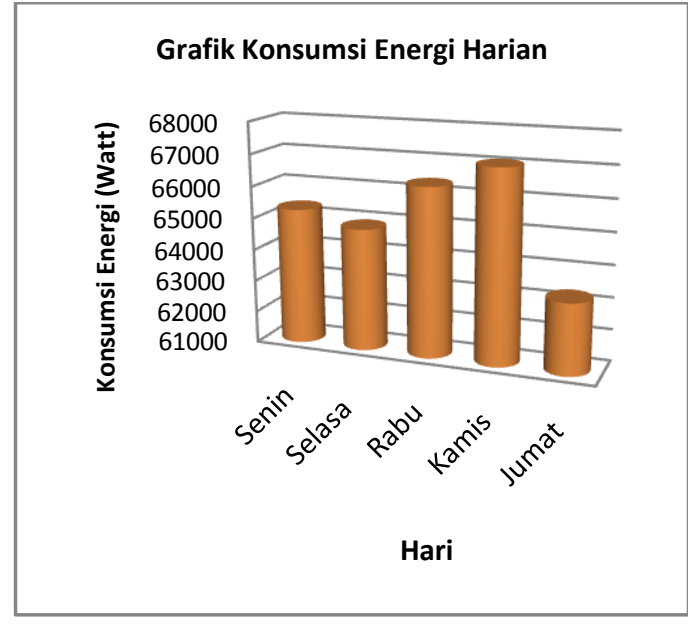

Gambar 7. Grafik konsumsi energi harian di gedung praktik.

Besar Intensitas konsumsi energi tiap gedung diperlihatkan pada tabel 6 .

Tabel 6. Tabel intensitas konsumsi energi (IKE) masing-masing gedung praktik SMKN 2 Pontianak.

\begin{tabular}{|c|l|c|c|c|}
\hline \multicolumn{5}{|c|}{ Intensitas Konsumsi Energi (IKE) Gedung Praktik SMKN 2 Pontianak } \\
\hline No. & Gedung Praktik & Luas $\left(\mathrm{m}^{2}\right)$ & $\mathrm{kWh}$. tahun & IKE \\
\hline 1 & Ketenagalistrikan & 654.5 & 32385.6 & 49.48144 \\
\hline 2 & Elektronika & 697 & 52956.8 & 75.97819 \\
\hline 3 & Otomotif & 901 & 107773.12 & 119.615 \\
\hline 4 & Komputer & 90 & 36961.6 & 238.7625 \\
\hline 5 & Gambar & 126 & 12209.6 & 96.90159 \\
\hline 6 & Broadcasting & 126 & 19510.4 & 154.8444 \\
\hline \multicolumn{7}{|c|}{ Total } & 2594.5 & 261797.12 & 99.75124 \\
\hline
\end{tabular}

Sumber : Olahan Data ( 2017 )

$\mathrm{kWh} \cdot \operatorname{tahun}=8 \mathrm{jam} / \mathrm{hr}, 5$ hari,52minggu/tahun.

4.2. Analisa Hasil Pengukuran.

Profil konsumsi penggunaan energi listrik total di gedung praktik SMK Negeri 2 Pontianak pada tahun 2016 mencapai $58616.50287 \mathrm{kWh}$ dengan nilai total biaya $\mathrm{Rp}$. 81.594.172. Rata-rata penggunaan energi listrik 4884.709 $\mathrm{kWh}$ per bulan dengan rata-rata biaya listrik bulanan $\mathrm{Rp}$. 6.799.514. Besarnya konsumsi dan biaya yang dibayarkan untuk energi listrik pada tahun 2016 berfluktuasi, tetapi cenderung mengalami stagnan. Hal ini disebabkan oleh banyaknya kegiatan yang dilakukan pada bulan-bulan tertentu, namun cenderung menurun pada akhir semester dan akhir tahun. Intensitas konsumsi energi apabila dilihat dari aspek IKE, penggunaan energi pada SMK Negeri 2 Pontianak masih tergolong sangat efisien. Hal ini dibuktikan dengan rata-rata IKE $8.29 \mathrm{kWh} / \mathrm{m}^{2} /$ bulan. Nilai IKE yang ditetapkan oleh SNI 6390:2011 untuk ruangan yang dikondisikan adalah $8.5-14 \mathrm{KWh} / \mathrm{m}^{2} / /$ bulan. Oleh karena itu, gedung SMK Negeri 2 Pontianak termasuk ke dalam kategori gedung perkantoran hemat energi. Profil beban listrik harian menunjukkan bahwa terdapat sedikit 
ketidaksesuaian beban antara hari senin sampai dengan hari jumat sehingga perlu penjadwalan penggunaan gedung praktik dengan memperhatikan besaran konsumsi energi listrik di setiap kompetensi keahlian. Beban listrik di sekolah pada umumnya mulai dinyalakan pada pukul 07.00 WIB dan dimatikan pada pukul 16.00 WIB.

Peluang penghematan energi dengan cara tidak menyalakan lampu pada saat cuaca cerah karena rata-rata ruangan mendapatkan cahaya matahari yang cukup melalui jendela kaca karena tidak terlindungi oleh pohon, kita perkirakan jam 10.00 WIB sampai dengan jam 14.00 WIB sekitar empat jam maka total daya lampu 4x19,120 = $76,48 \mathrm{kWh} /$ hari. Jika tarif daya listrik per $\mathrm{kWh}$ adalah Rp1467,28, (tarif tenaga listrik 2017 oleh PLN ) jumlah energi yang bisa dihemat dalam seminggu adalah 76,48 kWh x 5 hari x Rp1467,28, = Rp561.087.867 per minggu atau sebesar Rp29.176.569,344 per tahun. Konsumsi energi listrik pada pendingin ruangan (AC) tidak begitu besar dibanding konsumsi energi listrik peralatan lainnya disebabkan penggunaan AC hanya pada ruangan tertentu saja.

\section{Kesimpulan}

1. Hasil manajemen beban pada SMK Negeri 2 Pontianak menunjukkan bahwa pengurangan tingkat pencahayaan, mementukan waktu dari penggunaan peralatan dan perlengkapan ( penjadwalan pemakaian gedung ) dapat menghindari beban puncak dan mengefektifkan berbagai jenis penggunaan sarana dan juga mengurangi pembayaran tagihan listrik.

2. Pada hasil perhitungan, IKE yang didapat 99.75 $\mathrm{kWh} / \mathrm{m}^{2} /$ tahun belum melebihi dari standard IKE. Standar IKE untuk gedung perkantoran sekolah yaitu batas bawah $195 \mathrm{kWh} / \mathrm{m}^{2} /$ tahun, acuan 235 $\mathrm{kWh} / \mathrm{m}^{2} /$ tahun dan batas atas $265 \mathrm{kWh} / \mathrm{m}^{2} /$ tahun. Jadi penggunaan peralatan listriknya masih bisa ditingkatkan lagi atau lebih dimaksimalkan.

3. Pada penyusunan jadwal proses belajar mengajar dalam penggunaan ruangan di gedung praktik mempengaruhi keseimbangan beban.

\section{Referensi}

[1]. Wayne C Turner dan Steve Doty.2006. Energy Management Handbook. Sixth Edition.

[2]. Thumann, Albert,P.E.,C.E.M \& William J. Younger,C.E.M.2003. Handbook Of Energi Audits. Sixth Edition.

[3]. Zuhal. 1991, Dasar Tenaga Listrik. Bandung ITB.

[4]. Sulasno. Ir. 1991, Teknik Tenaga Listrik. Semarang. Satya Wacana.

[4]. Gellings, P.E., and J.H. Chamberlin. 1993. "Demand Side Management, Concepts \& Methods". Oklahama : Pennwell Publishing Company

[5]. Magdalena, M, 2009. Menekan Konsumsi dengan Audit Energi. 13 Juni 2009. Diakses 09 November 2017 dari http://puspiptek.info/?nq =id /node/359

[6]. Menteri Energy Sumber Daya Mineral Indonesia. 2012. Nilai IKE Standar di Bangunan Gedung Perkantoran Pemerintah Berdasarkan Permen ESDM No. 13/2012. Sumber : http://prokum.esdm.go.id /permen/2012/.pdf

[7]. Badan Standardisasi Nasional, 2000, SNI 03-6196-2000, "Prosedur Audit Energi Pada Bangunan Gedung", Jakarta, BSN

[8]. Departemen Pendidikan Nasional, 2006, "Teknik Penghematan Energi Pada Rumah Tangga dan Gedung", Jakarta, DPN 